\title{
The impact of cutting prior to goat grazing on variegated thistle (Silybum marianum)
}

\author{
Rose Greenfield ${ }^{\star}$, Katherine Tozer, Gosia Zobel, Catherine Cameron, Elizabeth North \\ AgResearch, Ruakura Research Centre, Private Bag 3123, Hamilton 3240, New Zealand \\ ${ }^{*}$ Corresponding author: rose.greenfield@agresearch.co.nz
}

\begin{abstract}
Variegated thistle (Silybum marianum) is a prevalent weed on the East Coast of the North Island of New Zealand. Goats may provide a novel management tool to control thistles, but little is known about how cutting thistles prior to grazing affects thistle consumption by goats. This study investigated the extent to which goats consume either uncut entire variegated thistle plants or cut thistles. Eight groups of three goats were presented with thistle vegetation in each of two replicate 1-hour feeding sessions on 2 consecutive days. Averaged over both days, in the cut treatment, goats consumed 99\% of the leaves that had been removed from the thistles and reduced the ground cover of the thistle plants by $68 \%$. In the uncut treatment, ground cover of the thistles was reduced by $46 \%$. A combination of cutting and goat grazing is likely to be a useful tool for stopping variegated thistle debris from smothering pasture and for inhibiting seed setting. Further work is required to test this at paddock scale.
\end{abstract}

Keywords Variegated thistle, novel weed control, Saanen, thistle management, hill country, weed control

\section{INTRODUCTION}

With the expansion of dairy farming, as well as escalating costs of farming in general, sheep and beef farmers must obtain greater value from New Zealand hill country for their farms to remain viable. A major constraint is the prevalence of pernicious weeds that compromise pasture growth and increase herbicide costs. Thistles are perhaps the most significant weed of hill country, infesting millions of hectares of hill-country pastures throughout the North and South Islands (Bourdôt et al. 2007). In some areas, variegated thistles (Silybum marianum) are a particular problem. For example, in the East Coast of the North Island, variegated thistles are classified as a "progressive containment and a sustained control weed" (Gisborne District Council 2019). With increasing concern over environmental stewardship and consumer preference for nonchemical control methods, cost-effective and environmentally sustainable control methods are required.

On less steep country, mowing has been shown to be effective (Bourdôt \& Rural News Group 2015). Repeated mowing will reduce thistle populations but timing is important and the thistle clippings can smother the pasture. This approach is, however, not feasible for steeper country. In hill country, manual cutting and slashing have been the main alternatives to herbicide. Using browsing animals like goats, however, may be an effective and less labourintensive option.

Some studies have shown that goats graze variegated thistles and can reduce their prevalence in pasture. In degraded pastures in Australia dominated by barley grass (Critesion murinum), brome grasses (Bromus spp.) and wild oats (Avena fatua), mixed grazing with two-thirds Cashmere goats and one-third sheep reduced thistle growth when compared to grazing with sheep alone. Compared to sheep-only grazing, mixed stocking 
reduced the diameter and height of the thistles during the vegetative stage and the number of seed heads per plant from 27 to 3 during the reproductive stage (Holst \& Allan 1996). Further, in swards grazed by sheep, variegated thistle ground cover increased from approximately $10 \%$ to $40 \%$ between July and December, while that in goat-grazed swards declined from $10 \%$ to near $0 \%$ over the same period (Holst \& Allan 1996). Goats also had a strong effect on thistle stem density and flowering frequency in New Zealand pastures (Rolston et al. 1981). Defoliation of rosettes was limited but became intensive once the reproductive phase began for three species of thistles (Californian (Cirsium arvense), marsh (C. palustre) and Scotch thistle (C. vulgare)). Goats actively select seed heads (Stanley et al. 2000) and when the seed heads are ingested by goats only $0.5 \%$ of the thistle seeds that are excreted are viable (Harrington et al. 2011). Survival of seed in the soil seedbank is at least nine years (Bruzzese \& Darby 2002), so sustained prevention of seeding is likely to be required over large areas to have significant impacts on thistle re-infestation of pastures. As variegated thistle mainly behaves as an annual (James \& Tozer 2018), preventing flowering and seed dispersal is critical for the control of this weed. These results suggest that goats could be a useful tool to reduce variegated thistle populations in New Zealand hill country.

In principle, integration of grazing and cutting may provide even better control of variegated thistle in flatter country (mow+graze) as well as in steeper country (cut+graze). If thistles are cut late in the season, before reproductive development (i.e. before the flowering stems start to elongate), it may be possible to prevent flowering, since thistle plants may have insufficient time to regrow and produce as many viable seeds (Davidson 1990; Dodd 1989). Using goats to graze the thistle clippings would reduce the impact on pasture growth by limiting the shading of desirable pasture species. However, this integration of grazing and cutting has never been experimentally tested. Therefore, a proof-ofconcept study was set up to investigate the relative palatability of cut variegated thistle vegetation versus intact (uncut) thistle plants to goats.

\section{METHODS}

\section{Trial site}

The trial took place at Ruakura Research Centre near Hamilton. The site consisted of pastures $>25$ years old, comprising mainly of perennial ryegrass (Lolium perenne), paspalum (Paspalum dilatatum), browntop (Agrostis capillaris) and broad-leaved plantain (Plantago major). The soil type was a Hamilton clay loam with a $\mathrm{pH}$ of 5.7 and an Olsen $\mathrm{P}$ of $21 \mathrm{mg} / \mathrm{L}$. Monthly rainfall in October, November, December, January, February and March was 53, 78, 186, 23, 14 and $29 \mathrm{~mm}$, respectively (based on data from the Ruakura weather station). Rainfall was below the long-term average of $66 \mathrm{~mm}$ for February and above the long-term average of $102 \mathrm{~mm}$ for December. On average this period was $12-\mathrm{mm}$ drier per month than the 25-year average (19912015).

The trial consisted of three phases:

1. Thistle Sourcing, Establishment and Management.

2. Goat Acclimatisation - the goats were fed leaves cut from transplanted plants to introduce them to thistle leaves wilted for various lengths of time.

3. Feeding Phase - the goats grazed plants established from seed to assess the relative palatability of attached leaves and cut wilted leaves, and to test the effect of grazing and mowing on the survival of the plants.

\section{Thistle source, establishment and management} Live thistles and thistle seeds were collected from the same farm, $20 \mathrm{~km}$ north of Gisborne.

For the Acclimatisation Phase, live variegated thistle plants (rosette diameter approx. $15 \mathrm{~cm}$, root depth around $10 \mathrm{~cm}$ ) were removed in October 2018, kept moist and transplanted into a paddock at Ruakura within 2 days.

For the Feeding Phase, variegated thistles were grown from seed collected in summer 2016. One hundred and twenty variegated thistle seeds were 
sown on 20 September 2018 (one per pot $7 \mathrm{~cm}$ x $7 \mathrm{~cm}$ x $8 \mathrm{~cm}$ deep) in potting mix and watered daily to drip point. Plants were maintained in a glasshouse with ambient light conditions. The temperature in the glasshouse was maintained between a minimum of $15^{\circ} \mathrm{C} \pm 1^{\circ} \mathrm{C}$ and maximum of $25^{\circ} \mathrm{C} \pm 1^{\circ} \mathrm{C}$. The germination percentage was $96 \%$, with 116 of the 120 thistle seeds germinating within a 48 -hour period within 3 days of sowing. Thistle seedlings were planted into the field site on 24th October 2018 when they had two true leaves. A total of 64 seedlings were planted, eight in each of the eight replicates, with a survival rate of $97 \%$. Pasture and the top $5 \mathrm{~mm}$ of soil was removed with a spade within a $30 \mathrm{~cm}^{2}$ area and the soil cultivated to a depth of $30 \mathrm{~cm}$. A thistle was planted into the centre of each prepared area and irrigated with $500 \mathrm{~mL}$ water.

All thistles had Thrive fertiliser (Yates, New Zealand) applied weekly until the beginning of November (at a rate of $90 \mathrm{~g} / \mathrm{L}$ in $500 \mathrm{ml}$ water, N: 25.0, P: 5.0, K: 8.8\%w/w + trace elements). From November, Thrive for Flowering Plants fertiliser (N: 14, P: 2.6, K: 21\%w/w) was applied weekly at the same rate until the Feeding Phase began in February. Slug bait (SlugOut, active ingredient 15 $\mathrm{g} / \mathrm{kg}$ of metaldehyde; NuFarm NZ) was applied at the recommended rate. Feeding Phase thistles were on average $65 \mathrm{~cm}$ in width and $14 \mathrm{~cm}$ high at the beginning of the Feeding Phase and no thistles had bolted.

\section{Goat acclimatisation}

Female Saanen-cross, 4 to 6-year-old, nonlactating goats from the Ruakura herd were used as they were familiar with the paddocks and facilities in the trial. Acclimatisation of the goats to the thistle treatments was done in a pen (3.6 m W x $4.8 \mathrm{~m} \mathrm{~L} \mathrm{x} 1.8 \mathrm{~m} \mathrm{H}$ ). Each group of three goats went into an indoor pen in the same order, beginning at 0830 each day. The goats were exposed over 4 consecutive days to each of the four thistle forage treatments (fresh-cut thistle, or Cut 1, 2 or 3 days before feeding). On the fifth day, the goats were offered all the thistle treatments simultaneously. For all thistle treatments, leaves

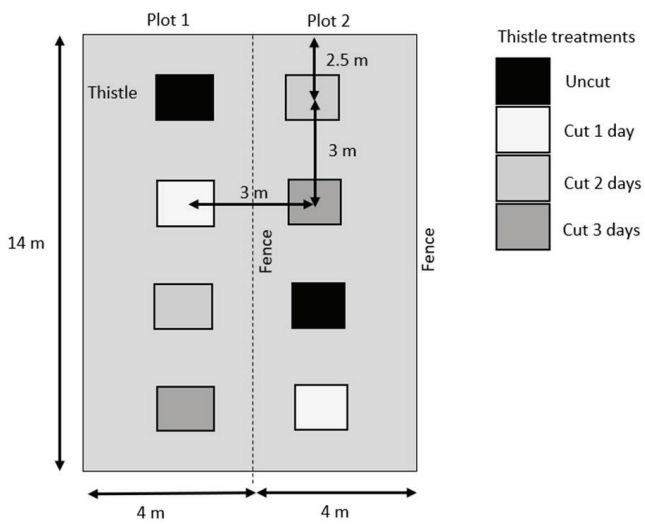

Figure 1 Replicate and paired plot design. Treatments were applied randomly in each of the 8 replicates. Goats had access to one plot on day 1 and the other plot on day 2. The remainder of the plot is mown pasture and the replicates were fenced using a 4-wire electric fence.

were chopped up and 2-3 pieces (approx. $6 \mathrm{~g}$ ) were presented in identical containers. After each day of acclimatisation, the goats were given ad libitum access to pasture. At 1600, they were taken off the pasture and provided with a half bale of grass hay.

\section{Feeding phase}

The design was a randomised complete block design, with eight replicates each of two paired plots (Fig. 1). Goats were assigned randomly to the replicates as eight groups of three animals each - goats remained in their same group of three from the acclimatisation period. Each group had access to one of the plots of each pair on the first day (21 Feb) at 0900 for 1 hour, after which they were moved into a neighbouring paddock. The goats grazed the remaining plot of each pair on the second day (22 Feb).

There were four thistle treatments within each $14 \mathrm{~m} \mathrm{x} 4 \mathrm{~m}$ plot: Uncut or Cut 1, 2 or 3 days before feeding. For the Cut treatments, approximately half of the leaves of each thistle (average $47 \mathrm{~g}$ ) were excised at the junction between the leaf and stem and left on the ground where they "fell" next to the thistle from which they were cut. Thus, each 'Cut' treatment comprised a mixture 
of excised and attached leaves, simulating a damaged thistle plant. Thistles were positioned along a longitudinal transect down the centre of each plot, with $3 \mathrm{~m}$ between each thistle base and a $2.5 \mathrm{~m}$ gap between the end of the transect and the fence (Fig. 1). The pasture in each plot was mown to $4 \mathrm{~cm}(\sim 1100 \mathrm{~kg}$ of dry matter/ ha) and grass clippings removed the day before the beginning of the Feeding Phase, so that goats had negligible pasture available.

Three days after the end of the Feeding Phase, all thistles in the Cut treatments were cut off at ground level to simulate normal mowing techniques. Thus, the Cut-1 treatment was mown again five days after initial cutting, the Cut-2 treatment at 6 days and the Cut- 3 treatment at 7 days.

\section{Measurements}

The height and diameter (widest point of rosette) of each thistle was measured before and after each Feeding Phase. Plant survival was recorded before the Feeding Phase began and periodically up to 4 weeks afterwards.

The percentage ground cover of each thistle plant in the plot was assessed using a $1 \mathrm{~m}^{2}$ quadrat with $5 \times 5 \mathrm{~cm}$ cells. The thistle herbage was photographed within a $1 \mathrm{~m}^{2}$ quadrat and analysed in the program 'Image J' (National Institutes of Health, USA) to quantify the ground cover both before and after grazing, and to calculate the reduction in ground cover during grazing. Variegated thistle plants were scored for vigour before grazing: 1 = green; $2 \leq 50 \%$ of the total number of leaves were yellowing; $3>50 \%$ of total number of leaves were yellow or dead.

To assess the palatability of thistle leaves that were attached or had been cut and wilted, a 'typical' leaf was selected from each treatment, excised if necessary, weighed and the leaf photographed on a white background for measurement of leaf curvature before snap-freezing in liquid nitrogen. Samples were stored at $-20^{\circ} \mathrm{C}$ prior to freeze drying. Each dried leaf was ground in a Cyclone Sample Mill (UDY Corp., USA) with a $1 \mathrm{~mm}$ sieve and bulked with the same treatment from another replicate (to give a total of four bulked samples for each treatment for the first day of the Feeding Phase). Low and high molecular weight water soluble carbohydrate analyses were done using the anthrone method (Thomas 1977), which was modified to use a combined water and ethanol-based extraction procedure (Parsons et al. 2004). For leaf-curvature analyses, a line was drawn on each photo in the computer program ' $\mathrm{R}$ studio' ( $\mathrm{R}$ studio Inc.) depicting the curvature of the central midrib of each thistle leaf in a two-dimensional (X-Y) plane. The X and Y coordinates at centimetre intervals along the curve were recorded for subsequent statistical analyses.

\section{Statistical Analysis}

Data were analysed by analysis of variance using Genstat (18th edition) with a split-plot design that fitted paddock, replicate within paddock and grazing plot within replicate as random variables, and thistle treatment as the fixed variable. There was no difference between the first and second day in any of the variables measured so data were averaged over both days and the averages analysed. Plant-survival data were analysed by a binomial regression with fixed dispersion of 1. A mixed model smoother function was used to estimate the influence of the number of days since the thistle was cut on the leaf curvature.

\section{RESULTS}

At the beginning of the study, all variegated thistle plants were vegetative with an average diameter of $65 \mathrm{~cm}$ and height of $14 \mathrm{~cm}$. The proportions of green, senescing and dead leaves were similar in all treatments before grazing (averaging 63\% green, $13 \%$ senescing and $24 \%$ dead, $\mathrm{P}>0.05$ ).

Immediately after the Feeding Phase, $94 \%$ of Uncut thistles and $37 \%$ of Cut-1 thistles survived. No thistles in the Cut-1 treatment recovered from being cut off at ground level on day 5. Only 19\% of Uncut thistles survived during the following 4-weeks, and no other thistles re-grew (Table 1).

Nearly all available thistle leaves from plants cut 1, 2 or 3 days prior to grazing were consumed ( $>98 \%$ of cut biomass, Table 1) and there was no difference between the three treatments in the amount consumed $(\mathrm{P}>0.05)$. The ground cover 
Table 1 Effect of goat grazing on uncut variegated thistle and variegated thistle cut 1,2 and 3 days before grazing. Measurements include the percentage survival of thistle plants from the day before the Feeding Phase (Day 0), on day 3 after the Feeding Phase ended, day 5 once plants were cut to ground level and at 4 weeks after the Feeding Phase. The percentage of thistle biomass consumed (leaf consumed \%); the reduction in thistle ground cover during grazing (pre-grazing area - post-grazing area (area loss \%)); \%DM of the thistle leaves; and the concentration of low molecular weight (WSC low), high molecular weight (WSC high) and total water-soluble carbohydrate (WSC total) on the first day.

\begin{tabular}{|c|c|c|c|c|c|c|}
\hline Variegated thistle measurement & Uncut & Cut 1 & Cut 2 & Cut 3 & SED & P-value \\
\hline \multicolumn{7}{|c|}{ Survival of thistle plants (\%) } \\
\hline Before & 100 & 100 & 100 & 81 & 10.8 & 0.021 \\
\hline After 3 days & 94 & 36 & 0 & 0 & 21.62 & $<0.001$ \\
\hline After 5 days & 94 & 0 & 0 & 0 & 6.25 & $<0.001$ \\
\hline After 4 weeks & 18.8 & 0 & 0 & 0 & 6.25 & 0.007 \\
\hline \multicolumn{7}{|c|}{ Grazing impacts (\%) } \\
\hline Leaf consumed & * & 99 & 100 & 98 & 1.2 & ns \\
\hline Area loss & 46 & 71 & 63 & 71 & 5.8 & $<0.001$ \\
\hline \multicolumn{7}{|c|}{ Pre-grazing leaf quality } \\
\hline Leaf DM (\%) & 9 & 36 & 51 & 60 & 5.3 & $<0.001$ \\
\hline WSC low (mg/g) & 7.4 & 14.9 & 14.4 & 20.8 & 2.70 & $<0.001$ \\
\hline WSC high (mg/g) & 0.7 & 1.5 & 2.2 & 2.6 & 0.65 & 0.033 \\
\hline WSC total (mg/g) & 8.1 & 16.3 & 16.6 & 23.4 & 2.90 & $<0.001$ \\
\hline
\end{tabular}

${ }^{*}$ not measurable since no record of the quantity of leaf consumed was possible.

of the thistles declined in response to grazing. Overall, ground cover was reduced to a greater extent in the three Cut treatments than in the Uncut treatment (average of $68 \%$ reduction in ground cover in Cut treatments vs $46 \%$ in the Uncut, $\mathrm{P}<0.001)$.

Leaf dry matter increased (i.e. the moisture content declined) as the days after cutting increased $(\mathrm{P}<0.001)$. Leaf $\mathrm{DM}$ comprised approximately $9 \%$ in the Uncut and increased to up to $60 \%$, when thistle leaves were cut 3 days before feeding (Table 1).

The concentrations of low molecular weight and total water-soluble carbohydrate were generally lowest in the Uncut, intermediate when cut 1 or 2 days prior to feeding and highest when cut 3 days prior to feeding $(\mathrm{P}<0.001$; Table 1). A similar pattern was observed in the high molecular weight water-soluble carbohydrates, although the effect was less pronounced $(\mathrm{P}<0.033)$.
There was an effect of treatment on the curvature of the leaf, with the three cut treatments being similar and much more curved than the uncut control (Fig. 2).

\section{DISCUSSION}

Variegated thistle management plans typically do not focus on using grazing animals as a control method. This may be, in part, because thistles are toxic to sheep (Bruzzese \& Darby 2002). However, variegated thistles are not toxic to goats and are therefore a potential control option (Arviv et al. 2016). Goats used in trials to graze thistles typically require pre-conditioning. For example, Arviv et al. (2016) found that goats preconditioned to eating variegated thistles indoors were $50 \%$ more likely to consume thistles outdoors than non-conditioned goats (30\% vs. $21 \%$ thistles consumed respectively). The goats in our study were only briefly introduced to thistles for the 5 days prior to the trial, not intensively 


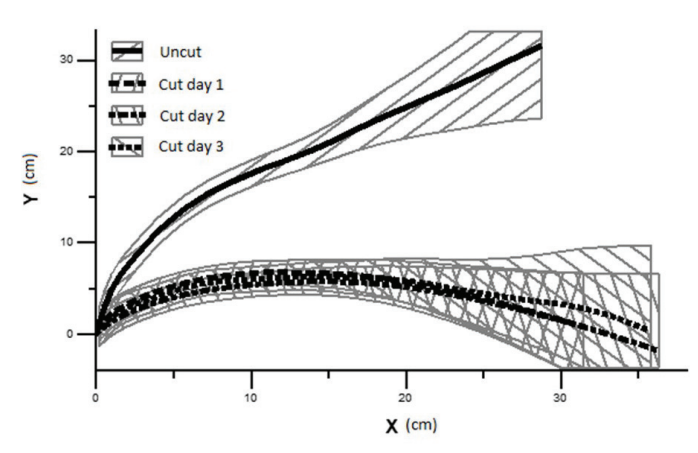

Figure $2 \mathrm{X}$ and $\mathrm{Y}$ are measured in $\mathrm{cm}$ and indicate the shape of the thistle for the four treatments in a two-dimensional plane. Hatched bands are 95\% Least Significant Difference intervals. Two curves are significantly different at the $5 \%$ level where the bands do not overlap.

pre-conditioned, but still ate nearly all of the thistle leaves available, especially those that had been previously excised. This finding suggested that cutting the variegated thistle plants combined with goat grazing could be an effective control mechanism. Most of the thistles in the Cut treatments died after the Feeding Phase and no regrowth occurred over the next 4 weeks. This was in contrast to the uncut plants, where most thistles survived the Feeding Phase.

Goats readily ate the leaves at 1,2 or 3 days after cutting. This result implies there is flexibility in the post-cutting grazing management to remove the cut thistles and goats can be brought into a paddock several days after cutting. Removal of thistle debris in this manner may limit the covering and shading of the pasture and avoid the creation of bare patches (Dingwall 1950). This type of management is important, as bare patches can be colonised by other undesirable weedy species, remain bare (James \& Tozer 2018 ), or be prone to re-infestation of variegated thistle the following autumn from seed in the seedbank (Pook 1983).

Excision of thistle leaves and up to 3 days of wilting had clear impacts on the physical and chemical attributes of the leaves. When handling the thistles, the research team noted that the cut wilted leaves were softer and less prickly, which was consistent with their change in shape. The change in these physical attributes of the thistles after cutting may have made it easier for the goats to consume them compared to the leaves that were left on the uncut thistle.

While the concentration of water-soluble carbohydrate in the leaves increased with days since cutting, it was not likely to be a significant factor for the goats, since they consumed the majority of cut leaves provided.

Goats also consumed the uncut thistle during the Feeding Phase period although there was less reduction in leaf area than if the leaves had been cut prior to grazing. The goats tended to eat more excised leaves, regardless of whether or not the leaves had been wilted prior to grazing. It is important to note that this study was not designed to assess preference; we encourage future work that provides ad libitum access to the various treatments in order to assess goat preference.

Integrating this knowledge into new variegated-thistle management plans needs to include consideration of other livestock classes too. On sheep and beef hill-country farms where variegated thistles are a problem, the paddock could be grazed by sheep or cattle to make the most profitable use of the pasture, and then the thistles slashed before the goats are put into the paddock. This could make goat grazing more effective as other potential forage is removed and the main food source is cut thistles.

In steeper country where slashing is not a viable option, spray-grazing may be a useful tactic. In spray-grazing, a sub-lethal dose of herbicide is applied aerially to a thistle patch (Anon 2007) resulting in the thistles wilting. The introduction of goats after spraying to consume the wilted thistles could result in the death of the thistle plants. Pasture survival is increased due to the thistles being grazed before shading of the pastures can occur. A combination spraygrazing with goat grazing has been suggested as a successful thistle-control technique in Australia (Anon 2007). Less herbicide needs to be applied with spray-grazing which has environmental 
and financial benefits. However, work is needed that evaluates the effect of herbicide use on consumption by the goats, as well as the effect on the goats themselves.

Fencing is a limiting factor with regards to goats, and the fencing infrastructure may need to be upgraded on typical sheep and beef farms. In the future, "virtual fencing" technologies may be able to contain the goats to the areas where they are needed.

For this knowledge to be confidently incorporated in to the farm weed-management toolbox, further study is required. In particular, the growth phases of the thistle plant used in this trial were somewhat different from that observed on the East Coast. Seeds were sown in early spring and the plants remained vegetative throughout the study period; this timeline differs from the East Coast season, where variegated thistle typically germinates in autumn and becomes reproductive in late spring. Timing of any control efforts are critical. Dodd (1989) found that immature variegated thistles with stems $<20 \mathrm{~cm}$ were still able to produce viable seed after simulated mowing and slashing in Australia. This highlights the importance of identifying the best time to cut the thistles so that they do not have time to regrow and produce seed before senescence - information that must be incorporated into any weed-management plans developed for farmers.

\section{CONCLUSIONS}

This initial proof-of-concept study showed that goats consumed up to $99 \%$ of the cut variegated thistle foliage. There is clearly potential to include grazing by goats in an integrated weed management strategy. However, further work should be done at paddock scale over a longer period on the East Coast within the typical variegated thistle season. This would enable a robust test of the effectiveness of goats in controlling variegated thistle and limiting pasture shading on commercial hill-country properties.

\section{ACKNOWLEDGEMENTS}

We would like to acknowledge the help and dedication that Trevor Watson, Regan Murney and Cassidy Corcoran showed in running the trial. Thanks to Martin Kear for growing and sowing the thistles, and to Tony Craven, Caitlyn Dawbin and Bridget Wise for taking measurements throughout the trial. We would also like to thank Trevor James, Warren King, Maryann Staincliffe and Martin Upsdell for their help and advice, and the AgResearch Curiosity Fund and MBIE C10x1806 for financing this trial.

\section{REFERENCES}

Anon 2007. Weed control using goats. A guide to using goats for weed control in pastures. Meat \& Livestock Australia Limited, 24.

Arviv A, Muklada H, Kigel J, Voet H, Glasser T, Dvash L, Ungar ED, Landai SY 2016. Targeted grazing of milk thistle (Silybum marianum) and Syrian thistle (Notobasis syriaca) by goats: Preference following preconditioning, generational transfer, and toxicity. Applied Animal Behaviour Science 179: 53-59.

Bourdôt GW, Fowler SV, Edwards GR, Kritticos DJ, Kean JM, Rahman A, Parsons AJ 2007. Pastoral weeds in New Zealand: status and potential solutions. New Zealand Journal of Agricultural Research 50: 139-161.

Bourdôt GW, Rural News Group 2015. Mowing an option? Rural News. https://www. ruralnewsgroup.co.nz/rural-news/ruralmanagement/mowing-an-option (accessed 24 April 2019).

Bruzzese E, Darby S (eds) 2002. Variegated thistle. Landcare Notes LC0187 (Feb 1998). Keith Turnbull Research Institute, Frankston. State of Victoria Department of Natural Resources and Environment. http://www.sgln.net.au/ wp-content/uploads/2017/03/Variegated_ thistle.pdf (accessed 24 April 2019).

Davidson S 1990. Goats help eliminate thistles. Rural Research 147: 16-19.

Dingwall AR 1950. Variegated thistle and its control. New Zealand Journal of Agriculture 81: 141-142.

Dodd J 1989. Phenology and seed production 
of variegated thistle, Silybum marianum (L.) Gaertn., in Australia in relation to mechanical and biological control. Weed Research 29(4): 255-263.

Gisborne District Council 2019. Variegated thistle. https://www.gdc.govt.nz/variegatedthistle/. Accessed 24 April 2019.

Harrington KC, Beskow WB, Hodgson J 2011. Recovert and viability of seeds ingested by goats. New Zealand Plant Protection 64: 7580.

Holst PJ, Allan CJ 1996. Targeted grazing of thistles using sheep and goats. Plant Protection Quarterly 11: 271-273.

James T, Tozer K 2018. Variegated thistle plant population density not correlated with soil bank seed density. New Zealand Plant Protection 71: 51-56.

Parsons AJ, Rasmussen S, Xue H, Newman JA, Anderson CB, Cosgrove GP 2004. Some 'high sugar grasses' don't like it hot. Proceedings of the New Zealand Grassland Association 66: 265-271.

Pook EW 1983. The effect of shade on the growth of variegated thistle (Silybum marianum L.) and cotton thistle (Onopordum sp.) Weed Research 23(1): 11-17.

Rolston MP, Lambert MG, Clark DA, Devantier BP 1981. Control of rushes and thistles in pastures by goat and sheep grazing. Proceedings of the NZ Weed and Pest Control Conference 34: 117-121.

Stanley DF, Holst PJ, Allan CJ 2000. The effect of sheep and goat grazing on variegated thistle (Silybum marianum) populations in annual pastures. Plant Protection Quarterly 15: 116118.

Thomas TA 1977. An automated procedure for the determination of soluble carbohydrates in herbage. Journal of the Science of Food and Agriculture 28: 639-642. 